\title{
E1A-Binding Protein P400
}

National Cancer Institute

\section{Source}

National Cancer Institute. E1A-Binding Protein P400. NCI Thesaurus. Code C118533.

E1A-binding protein p400 (3159 aa, 343 kDa) is encoded by the human EP400 gene. This protein plays a role in the modulation of transcription through the regulation of histone acetylation. 